\title{
Comparison of different telepathology solutions for primary frozen section diagnostic
}

\author{
P. Hufnagl *, G. Bayer, P. Oberbarnscheidt, \\ K. Wehrstedt, H. Guski, S. Hauptmann and \\ M. Dietel
}

Institute of Pathology, Charité, Medical Faculty of the Humboldt University Berlin, 10098 Berlin, Germany

In a retrospective study on a set of 125 cases we compared the following three telepathology solutions for primary frozen section diagnosis: ATM-TP (connection via ATM), TPS 1.0 (connection via LAN) and TELEMIC (connection via Internet), which represent different concepts of telepathological procedures.

A set of 125 routine frozen sections (breast) was selected from the Charité cases of the year 1999. Four experienced pathologists diagnosed retrospectively all of these cases using the ATM-TP and TPS systems and 53 of them with the TELEMIC system.

Using the ATM-TP we recorded no false positive $(0 \%)$, 4 false negative $(3.2 \%)$ and 4 deferred (3.2\%) cases. Using the TPS we recorded no false positive $(0 \%), 4$ false negative (3.2\%) and 4 deferred (3.2\%) cases. Using the TELEMIC we recorded in 53 cases no false positive $(0 \%)$, no false negative $(0 \%)$ and 16 deferred $(30.2 \%)$ cases.

The average time of 2.2 minutes per case using ATM-TP is also short enough for routine frozen section diagnostic. This is also true for the TPS system with 7.2 minutes per case.

Keywords: Telepathology, frozen section service, Internet, ATM video conferencing

\section{Introduction}

Telepathology is the practice of pathology at a distance, using telecommunication systems. Beginning with a simple exchange of images between pathologists in order to get a second opinion on selected fields of view, it ends with live inspection of a slide using

\footnotetext{
${ }^{*}$ Correspponding author.
}

remote control of a robotic microscope at the remote station $[7,14,17]$.

Three frozen section laboratories belong to the institute of pathology of the Charité. They are placed on different locations in Berlin in direct contact with the surgical units. This was the origin of the telepathological activities of our institute which resulted in several practical telepathology solutions. Based on different technological features these telepathology systems offer different ways for the remote pathologist to analyse the specimen. Based on practical use and comparative studies we try to find out about the relevant features for different telepathological applications.

Within a retrospective study on a set of 125 cases we compared the following three telepathology solutions for primary frozen section diagnosis:

- ATM-TP (connection via ATM),

- TPS 1.0 (connection via LAN),

- TELEMIC (connection via Internet).

Our aim is the investigation of the three systems (representing different concepts of telepathological procedures) as potential telepathology solution for routine use in frozen section diagnostic. We focused the comparison on diagnostic accuracy, time needed, handling, data processing and archiving. Macroscopic examination was not in the focus of the present study.

\section{Material and methods}

\subsection{Cases}

A set of 125 routine frozen sections (breast) was selected from the Charité breast cases of the year 1999. Four experienced pathologists diagnosed retrospectively all of these cases using the ATM-TP and TPS systems and 53 of them with the TELEMIC system. 
The pathologists used the original surgical request. It contained patient data, important clinical data and the diagnostic request. All cases have been remotely evaluated without prior knowledge of the original frozen section or definitive paraffin diagnosis.

\subsection{Equipment}

Within our study we used the following three telepathology systems.

\subsection{ATM based video-conferencing system (ATM-TP)}

The ATM-telepathology system is a special videoconferencing system. It was designed and developed at the Charité [3]. The system was designed with respect to the fact that the backbone of the Charite is an ATM network (ATM - asynchronous transfer mode, ATM components of Controlware $\mathrm{GmbH}$, Germany).

TV and audio signals are transformed into digital signals (ATM, asynchronous transfer mode), compressed and sent by ATM-audio-video-codecs (Cellware Broadband $\mathrm{GmbH}$, Germany). The receiving codec decompresses and retransforms the data into TV and audio signals. Due to the high transfer rate (155 Mbit/s) the ATM-solution allows a transfer of full size video images $(786 \times 625$ pixels $)$ in highest quality. Remote control was realized using the robotic microscope RXA (Leica Microsystems GmbH Wetzlar, Germany). The microscope is controlled by firmware running on PC using RS-232. The pathologist has access to the control panel on the remote PC by a separate LAN connection using Timbuktu application sharing (Farallon Communications Inc. USA). A scheme of the technical solution is presented in Fig. 1.

\subsection{TPS telepathology system, version 1.0 (TPS)}

The TPS system (developed by LEICA Microsystems in cooperation with the Charité) allows the static and dynamic transmission of images over TCP/IP via LAN, ISDN or Internet [4,5]. Within our study we used LAN (10 Mbit/s). The images with a resolution of $762 \times 508$ pixels have been compressed with JPEG (compression quality 75). The generation of overview images including complete slide overviews is possible. A topological mapping between overview images and images in different higher magnifications is realised. The actual position of the image viewed is visualized by a corresponding rectangle in the overview image. All relevant case data is stored in a database. A scheme of the system is shown in Fig. 2.

\subsection{Internet-based telemicroscope (TELEMIC)}

The TELEMIC system is an automatic microscope that is controlled by a computer which fulfills the function of an Internet server [20]. It was developed in our institute to demonstrate remote microscope control via the Internet. Every Internet user can access this server and is able to control the microscope by the use of an Internet browser with Java support (see Fig. 3).

The images are compressed with JPEG. It is possible to switch between small highly compressed images $(360 \times 270$ pixels, with a JPEG compression of 35$)$ or full size, high quality images $(720 \times 540$ pixels, with a JPEG compression quality of 75). The colour depth of both image formats is 24 bit.

The features of the telepathology solutions are summarized in Table 1.

\subsection{Workflow of the study}

For each case and each telepathology solution the diagnosing pathologist has been selected using a random procedure. All participating pathologists have been familiar with the telepathology solutions based on routine use for second opinion in frozen sections. The time for the examination of each case was recorded.

The diagnostic accuracy was assessed using the original paraffin diagnosis as "gold standard".

\section{Results}

\subsection{Diagnostic accuracy}

Table 2 shows the correlation between the definitive diagnosis and the different frozen section diagnoses (conventional frozen section diagnosis, ATM-TP based diagnosis, TPS based diagnosis, TELEMIC based diagnosis).

Using the ATM-TP we recorded no false positive (0\%), 4 false negative (3.2\%) and 4 deferred (3.2\%) cases. This corresponds to the accuracy of the conventional frozen section diagnostic. It shows that with respect to the diagnostic accuracy the ATM-solution is qualified for routine frozen section diagnoses.

Using the TPS we recorded no false positive $(0 \%)$, 4 false negative $(3.2 \%)$ and 4 deferred $(3.2 \%)$ cases. This corresponds as well to the accuracy of the conventional frozen section diagnoses.

Using the TELEMIC we recorded in 53 cases no false positive $(0 \%)$, no false negative $(0 \%)$ and 16 de- 
Frozen section laboratory

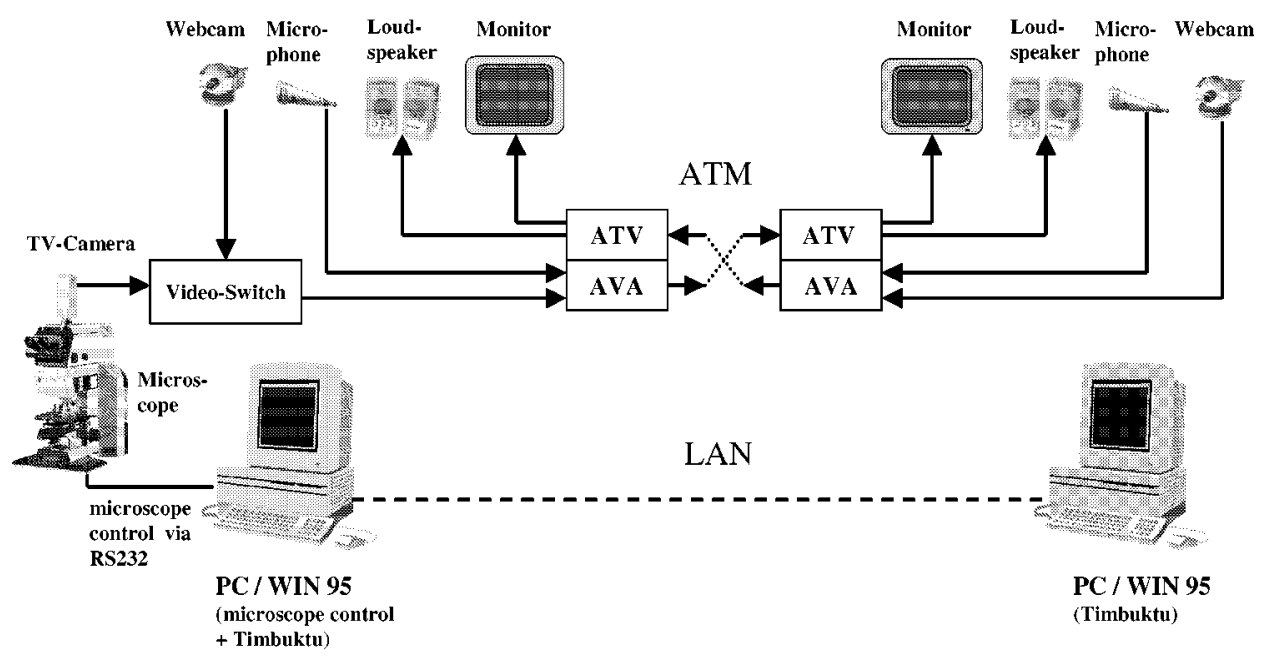

Fig. 1. Scheme of the ATM telepathology solution (ATV: codec from ATM to video/audio, AVA: codec from video/audio to ATM).

Frozen section laboratory

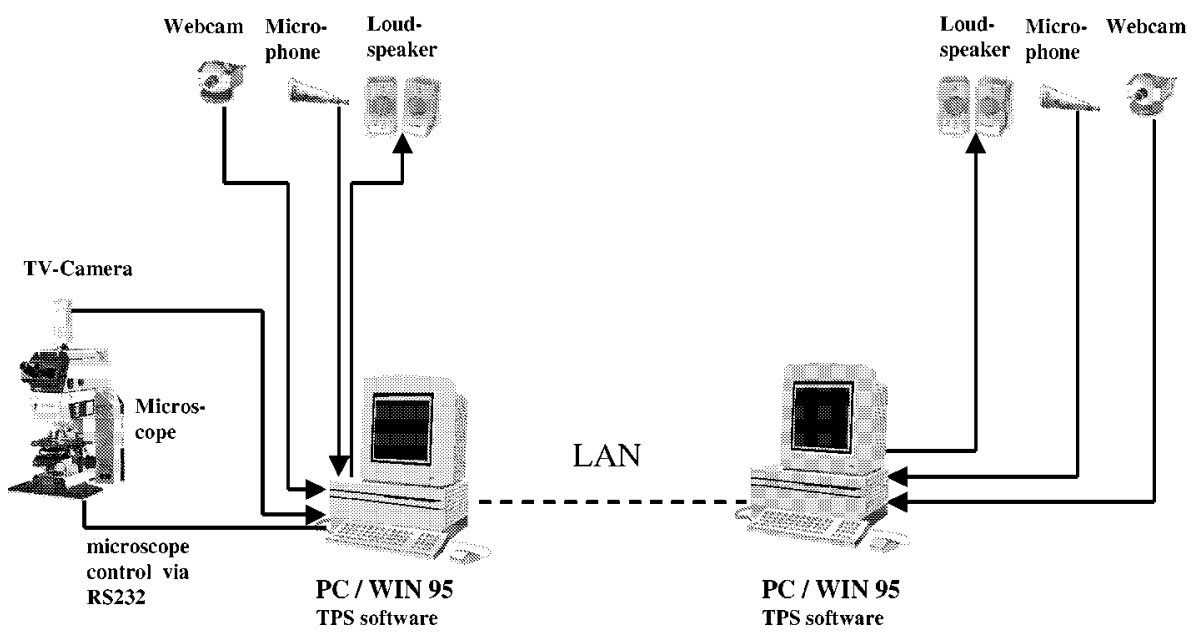

\section{Pathologist}

Fig. 2. Scheme of the TPS telepathology system. ferred $(30.2 \%)$ cases. The reason for the high rate of deferrals was the lack of an appropriate overview image. The pathologist was only able to find the diagnosis when there was a defined pathologic abnormality. If a pathological change wasn't detected, he could have easily overseen some important parts of the specimen. In practice there is no possibility for a close examination of the whole specimen within the real time limit.

The results listed in Table 2 for ATM-TP and TPS are in the range of conventional frozen section diagnostic.

\subsection{Time per case}

An overview about the time per case for the different telepathology solutions is given in Table 3. The average time of 2.2 minutes using ATM-TP is short enough for routine frozen section diagnostic. The average time using the TPS system was 7.2 minutes. This is also within the limit of routine frozen section diagnostic. The time measurements presented for the TELEMIC are not really representative because the pathologists tried to reject a case if clear malignant areas could not be found within an appropriate time limit. 


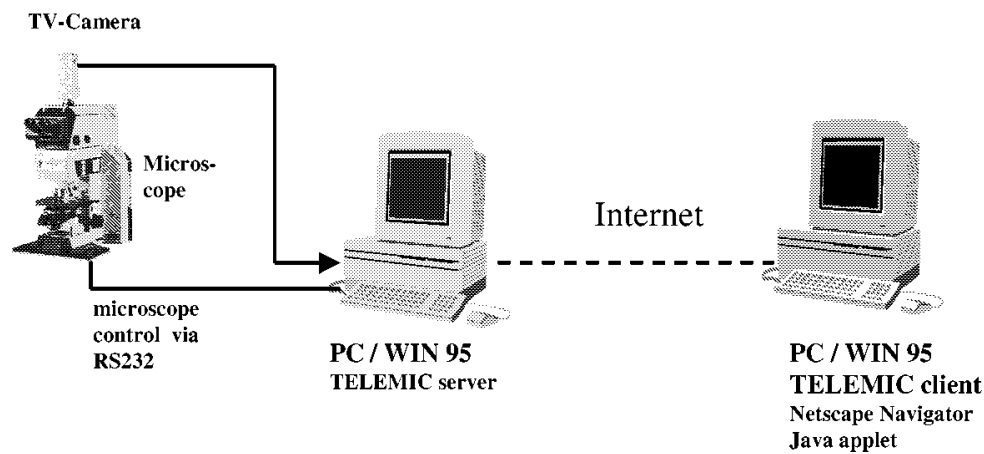

Fig. 3. Scheme of the TELEMIC telepathology solution.

Table 1

Overview about important features of the telepathology solutions

\begin{tabular}{|c|c|c|c|}
\hline Feature & ATM-TP & TPS & TELEMIC \\
\hline $\begin{array}{l}\text { Remote microscope } \\
\text { control }\end{array}$ & Yes & Yes & Yes \\
\hline $\begin{array}{l}\text { Dynamic image } \\
\text { transfer }\end{array}$ & $\begin{array}{l}\text { Live video and audio } \\
\text { connection in full } \\
\text { PAL resolution }\end{array}$ & $\begin{array}{l}\text { Live video and still } \\
\text { image transfer H.263, } \\
\text { H.264 }\end{array}$ & $\begin{array}{l}\text { No live video image } \\
\text { transfer }\end{array}$ \\
\hline $\begin{array}{l}\text { Static image } \\
\text { transfer }\end{array}$ & No & $762 \times 508$ pixels, 24 bit & $\begin{array}{l}720 \times 540 \text { pixels, } 24 \\
\text { bit }\end{array}$ \\
\hline Camera & $\begin{array}{l}3 \text { chip; Sony DXC- } \\
930 \mathrm{p}\end{array}$ & $\begin{array}{l}3 \text { chip; Hitachi HV- } \\
\text { C20M }\end{array}$ & $\begin{array}{l}3 \text { chip; Sony DXC- } \\
\text { 930p }\end{array}$ \\
\hline Overview image & No & $\begin{array}{l}\text { Yes, for the whole } \\
\text { specimen and in every } \\
\text { magnification }\end{array}$ & $\begin{array}{l}\text { Only for orientation } \\
\text { (snapshot of the } \\
\text { lowest } \\
\text { magnification) }\end{array}$ \\
\hline $\begin{array}{l}\text { Documentation of } \\
\text { data }\end{array}$ & No & $\begin{array}{l}\text { Documentation of data } \\
\text { in a database }\end{array}$ & $\begin{array}{l}\text { Documentation of } \\
\text { data as a file }\end{array}$ \\
\hline Archiving of data & No & Yes & No \\
\hline $\begin{array}{l}\text { Special hard- or } \\
\text { software }\end{array}$ & $\begin{array}{l}\text { Special hardware } \\
\text { necessary }\end{array}$ & $\begin{array}{l}\text { Special hard- and } \\
\text { software necessary }\end{array}$ & $\begin{array}{l}\text { No special hard- or } \\
\text { software necessary at } \\
\text { the client side }\end{array}$ \\
\hline
\end{tabular}

Table 2

Confusion table of definitive and telepathology diagnosis

\begin{tabular}{lrrrrrrrr}
\hline $\begin{array}{l}\text { Diagnostic } \\
\text { accuracy }\end{array}$ & \multicolumn{2}{l}{ ATM-TP } & \multicolumn{2}{l}{ TPS } & TELEMIC & $\begin{array}{c}\text { Conventional } \\
\text { frozen section } \\
\text { diagnosis }\end{array}$ \\
\hline Number of cases & 125 & $100 \%$ & 125 & $100 \%$ & 53 & $100 \%$ & 125 & $100 \%$ \\
False positive & 0 & $0 \%$ & 0 & $0 \%$ & 0 & $0 \%$ & 0 & $0 \%$ \\
False negative & 4 & $3.2 \%$ & 4 & $3.2 \%$ & 0 & $0 \%$ & 3 & $2.5 \%$ \\
Deferral & 4 & $3.2 \%$ & 4 & $3.2 \%$ & 16 & $30.2 \%$ & 5 & $4 \%$ \\
\hline
\end{tabular}


Table 3

Time per case

\begin{tabular}{llcc}
\hline $\begin{array}{l}\text { Time per case in } \\
\text { minutes }\end{array}$ & ATM-TP & TPS & TELEMIC \\
\hline Average time & 2.2 & 7.2 & 3.2 \\
Minimal time & 1 & 2 & 1 \\
Maximal time & 9 & 15 & 10 \\
\hline
\end{tabular}

\subsection{Handling}

The ATM-TP solution is easy to handle, very fast and stable. The time needed to learn the handling is about 10 minutes. The ATM-TP is switched on standby mode the entire day. The image of the remote microscope is presented permanently on a special monitor. The control panel of the robotic microscope is very simple and is presented within a window on the PC's desktop.

There is more time necessary to learn the handling of the TPS system (between 1 and 2 hours). There are several possibilities to control the remote microscope (direction buttons, mouse click on image area, moving a tracker within the overview image). Pathologists developed a personal style of using the system. Using the live video modus the workflow is similar to the conventional way of diagnosing. The pathologist can use the overview image to be sure that all interesting areas of the the slide have been seen.

As our experiences with different users all over the world have shown [11] the TELEMIC solution is easily learnt, even if the user hasn't had very much experience with computers before. Time to learn the handling is also about 10 minutes.

\subsection{Documentation/archiving}

There is no electronic documentation within the ATM-TP. That is the reason for the fact, that it is impossible to reconstruct the diagnostic path. After the diagnostic procedure no images or data can be stored or archived. In the case of a review, there is no possibility to reconstruct the images that were seen by the pathologist and which diagnosis was given.

Within the TPS, which was originally designed for routine use, images and case data can be documented. After archiving it is not possible to change any information of the data or diagnoses. For every case the diagnostic path can be reconstructed from the database and the participating partners are saved in the user administration database.
With the current version of TELEMIC, which is designed primarily for international exchange over the Internet using an ordinary webbrowser, it is also possible that any other Internet user can see and change the images, diagnoses and data of the patient. The images and data can be stored in a file, but there is not yet a function to archive them in a database.

\section{Discussion}

Telepathology is used to get a second opinion, for telediagnostic, quality assessment and teleeducation $[2,6-8,14]$. The virtual slide $[15,18]$ will be more or less the heart of the digital pathology of the future. But this needs some years of progressive development.

Daily practice in telepathology is dominated by various systems, which are incompatible and sometimes difficult to handle [19]. These systems are combinations of different technical solutions for telecommunication, remote microscope control, generation of overview images, video conferencing, annotations, database, etc. $[8,10,12,13]$. Consequently many different features exist, which may be used during a telepathological session. But which of these features are really needed for the routine frozen section diagnostic?

\subsection{Requirements on telepathology solutions for frozen section diagnostic}

The main requirements for frozen section diagnostic in routine use are:

- Nearly no false positive cases.

- Low rate of false negative cases, comparable to conventional frozen section diagnostic.

- Low rate of deferred cases, maximum twice the rate in conventional frozen section diagnostic.

- The time required for diagnosis must be short enough.

- To exclude malignancy the remote pathologist should have the possibility to inspect the whole specimen.

- The diagnostic procedure has to be reconstructable for legal reasons. The partners, the clinical background and the diagnosis must be fixed.

It makes no sense to demand exact rates for the number of false positive/false negative/deferred cases or the time limit. This depends on the diagnostic spectrum and the concrete situation. The standard has to be 
the conventional frozen section diagnostic. The investigation of reasons for errors in telepathology is essential. We are just investigating the influence of resolution and data compression on subjective image quality [1] and presented a first study on diagnostic errors in telepathology [9].

If the number of frozen section per day exceeds 20 , as it is for the two frozen section laboratories of the Charite, the time limit is about 5-10 minutes. From a small hospital for which we offer a frozen section service we receive about 2 requests per week. A reasonable time limit lies between 10 and 20 minutes per case

\subsection{Evaluation of the telepathology systems}

The ATM-TP solution offers a live video connection of excellent quality. It is robust, fast, and simple to handle. We use it inhouse for primary diagnosis and second opinion. Unfortunately there is no possibility to document and archive user, case, and session data, or to reconstruct a diagnostic history. With respect to legal problems this can not be the choice for frozen section service between juristic independent institutions. Beyond this the system needs ATM infrastructure. If this infrastructure is present, the costs of the ATM-TP system are about US\$ 80,000 (including 1 robotic microscope and 2 bidirectional ATM-codecs). The installation of the ATM infrastructure explicite for telepathology is far too expensive. The lack of the possibility to generate and view overview images is sometimes a limiting factor. The documentation of telepathologic diagnostic is in our institute primarily done with pen and paper and transferred later to the pathology information system.

The TPS fulfills more or less all requirements listed above. Nevertheless the system is more complicated in handling and needs more time to become familiar with it. We use it inhouse for second opinion in frozen sections (via LAN), for frozen section diagnostic for a small hospital near Berlin (via 2 ISDN lines), and for expert consultation with pathologists in $\mathrm{Mu}-$ nich and Gießen (via Internet). The price of two systems (including $2 \mathrm{PC}, 1$ robotic microscope) is about US\$ 70,000. For documentation and archiving we use an NT-server with backup system.

The TELEMIC solution is very easy to install and cheap (freeware) but due to the general access through the Internet it is not useful for frozen section diagnostic in the current version. Also the lack of overview images makes it often impossible for the pathologist to give an accurate diagnosis. There is no warranty for him not to miss that part of the specimen, which is important for the diagnosis. TELEMIC is an excellent tool for second opinion over the Internet between users worldwide (11) and also for tele-education [16]. For routine use in frozen section diagnostic the TELEMIC solution has to be expanded based on the implementation of a database for the handling of cases, images and overview images as well as user logins.

\subsection{Routine use of telepathology systems}

In real life the time which is needed for a primary diagnosis using telepathology solutions is longer than in the retrospective study presented here. Since 5 months we operate an frozen section service for a small hospital near Berlin using the TPS (connected by 2 ISDN lines). The average time per case without macroscopic preparation is 12.5 minutes. We recorded the same difference between real life and study also for the ATM$\mathrm{TP}$, as we found about 7 minutes necessary for the diagnosis of a case. Increased working experience decreases the mean time per case. This was reported by several authors $[6,13,16,17,20]$.

Based on our experiences we built an TPS telepathology network which includes two frozen section laboratories, fetal autopsy laboratory and 7 working places of pathologists and a NT Server for the database [5].

\section{References}

[1] D. Daniel, S. Judith, K. Wehrstedt, P. Hufnagl and M. Dietel, Influence of image resolution on image quality in telepathology, Elec. J. Pathol. Histol. 6(3) (2000), No. 003-08.

[2] M. Dietel, P. Hufnagl and T.N. Nguyen-Dobinsky, The UICC telepathology consultation center - a global approach to improving consultation for pathologists in cancer diagnosis, Cancer 89 (2000), 187-191.

[3] P. Hufnagl, Graschew, S. Rakowsky, W. Haensch, P.M. Schlag and M. Dietel, Second opinion telepathology on frozen sections as part of daily routine in a university institute, Elec. J. Pathol. Histol. 6(2) (2000), No. 002-09.

[4] P. Hufnagl, T.N. Nguyen-Dobinsky, B. Stock, F. Fiedle and M. Dietel, Das Telepathologiesystem TPS 1 für RoutineTelepathologie, Pathol. Res. Pract. 196 (2000), 450.

[5] P. Hufnagl and T.N. Nguyen-Dobinsky, Telepathology using TPS, Elec. J. Pathol. Histol. 6(3) (2000), No. 003-10.

[6] K. Kayser, M. Fritz and M. Drlicek, Aspects of telepathology in routinary work with specific emphasis on ISDN, Ach. Anat. Cytol. Pathol. 43 (1995), 216-218.

[7] K. Kayser, J. Szymas and R. Weinstein, Telepathology. Telecommunication, Electronic Education and Publication in Pathology, Springer-Verlag, 1999. 
[8] I. Nordrum, Real-time diagnoses in telepathology, Adv. Clin. Pathol. 2 (1998), 127-131.

[9] P. Oberbarnscheidt, P. Hufnagl, H. Guski, S. Hauptmann and M. Dietel, Analysis of errors in telepathology, Elec. J. Pathol. Histol. 6(3) (2000), No. 003-11.

[10] M. Oberholzer, H.R. Fischer and H. Christen, Telepathology: Frozen section diagnostic at a distance, Virchows Arch. $\mathbf{4 2 6}$ (1995), 3-9.

[11] I. Petersen, G. Wolf, K. Roth and K. Schlüns, Telepathology by the Internet, J. Pathol. 191 (2000), 8-14.

[12] P. Schwarzmann, J. Schmid and C. Schnörr, Telemicroscope stations for Telepathology based on broadband and ISDN connections, Ach. Anat. Cytol. Pathol. 43 (1995), 209-215.

[13] P. Schwarzmann, B. Binder, R. Klose and M. Kaser, Histkom - evaluation of active telepathology in fieldtests, Adv. Clin. Pathol. 2 (1998), 135-138.

[14] C. Sowter and C.A. Wells, Telepathology: assessment of the implications and applications of telepathology for practical diagnostic pathology, J. Clin. Pathol. 51 (1998), 714-715.
[15] J.H. Saltz, Digital pathology - the big picture, Editorial, Hum. Pathol. 31 (2000), 779-780.

[16] J. Szymas, G. Wolf, W. Papierz, M. Danilewicz and B. Jarosz, Feasibility of telepathology in neurooncological diagnosis: a prospective study allowing the analysis of histological images and cases to be viewed by several partners, Elec. J. Pathol. Histol. 6(3) (2000), No. 003-05.

[17] R.S. Weinstein, A.K. Bhattacharrya, A.R. Graham and J.R. Davis, Telepathology: A ten year progress report, Human Pathol. 28 (1997), 1-7.

[18] R.S. Weinstein, A futurist meets the 21st century: love at first sight, Hum. Pathol. 31 (2000), 1-2.

[19] C.A. Wells, Telepathology: a diagnostic tool for the millenium?, J. Pathol. 191 (2000), 1-7.

[20] G. Wolf, D. Petersen, M. Dietel and I. Petersen, Telemicroscopy via Internet, Nature 391 (1998), 613-614. 


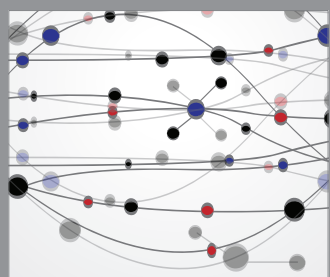

The Scientific World Journal
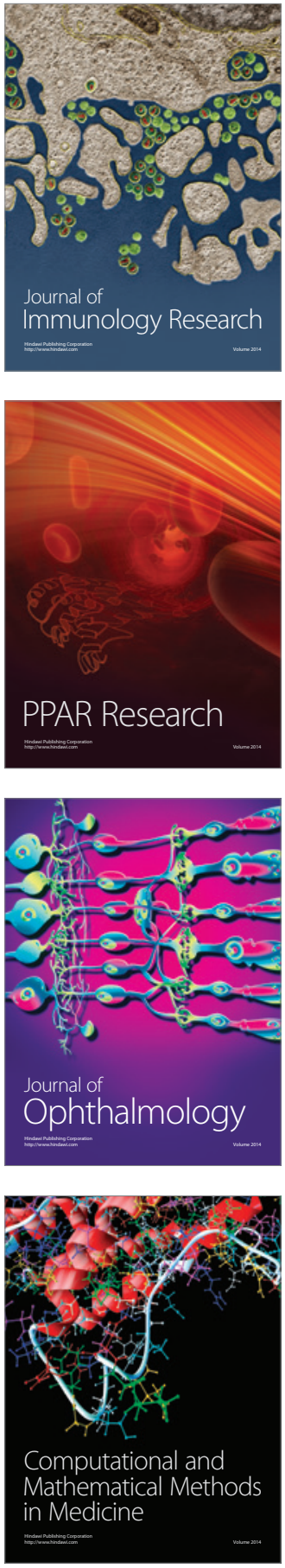

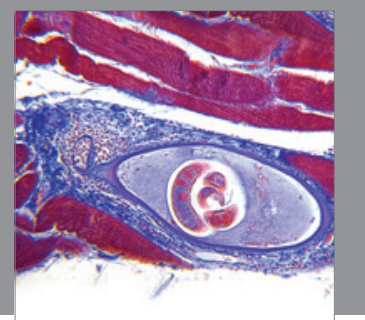

Gastroenterology

Research and Practice
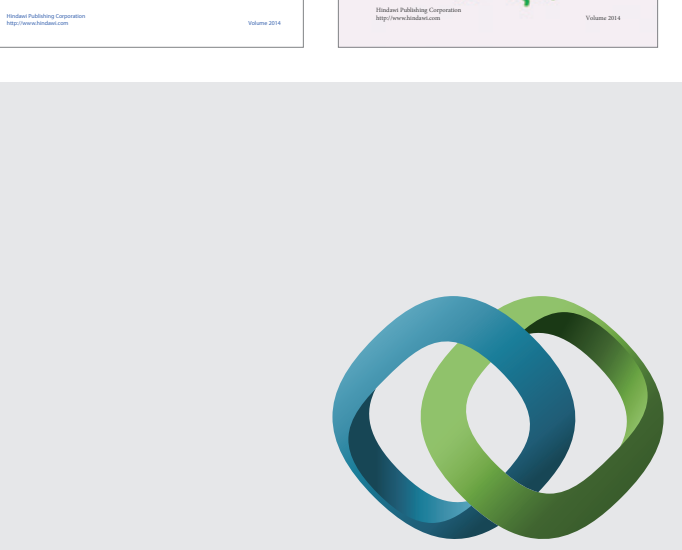

\section{Hindawi}

Submit your manuscripts at

http://www.hindawi.com
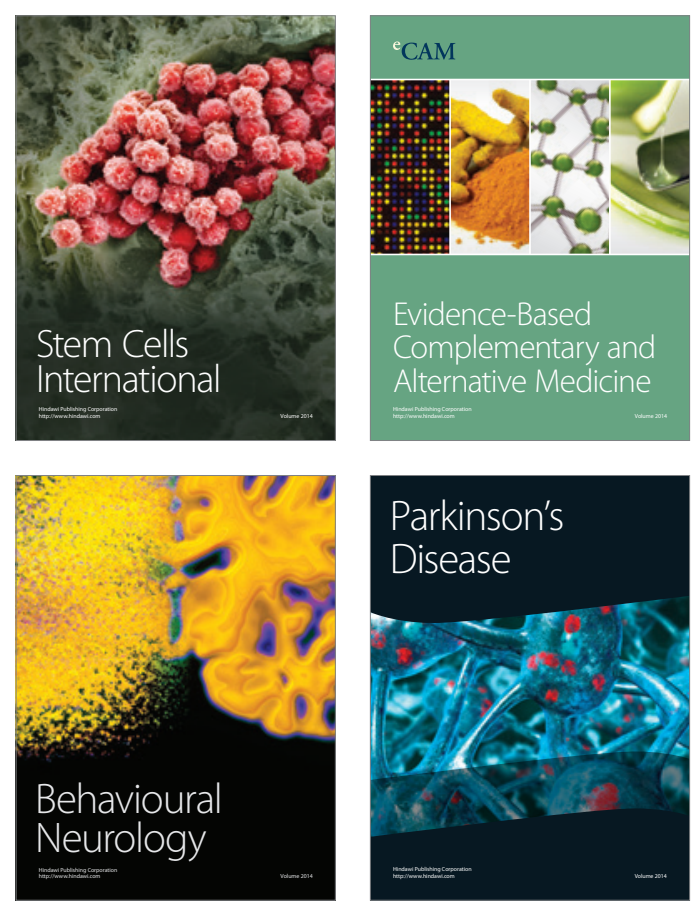

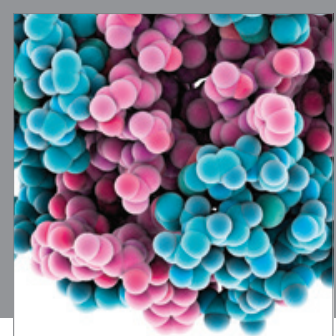

Journal of
Diabetes Research

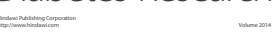

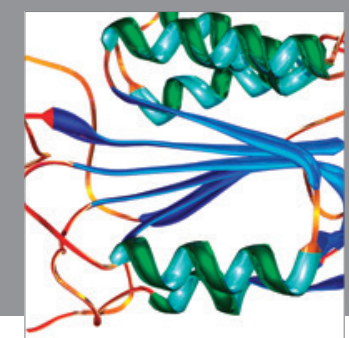

Disease Markers
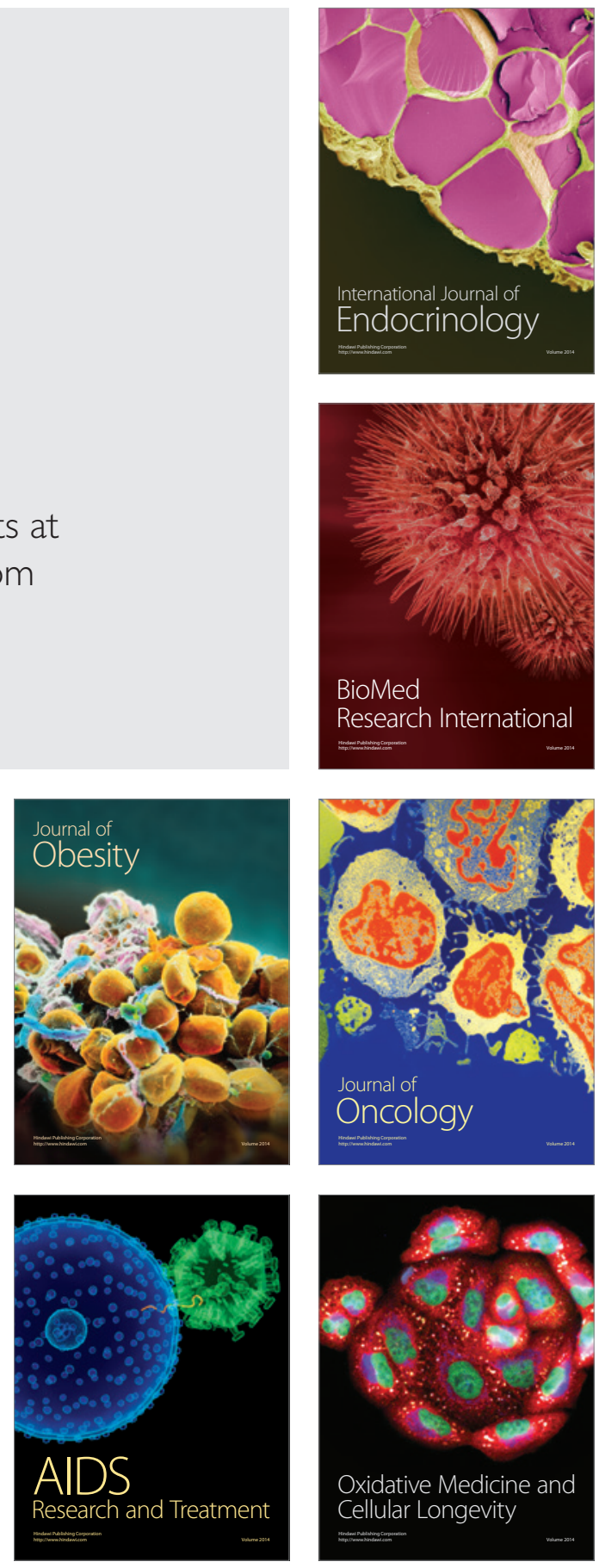